\title{
Electrospinning Synthesis of Ag Nanoparticles-doped Carbon Nanofibers for Voltammetric Determination of $\mathrm{H}_{2} \mathrm{O}_{2}$
}

\author{
Yanqiong Zhu ${ }^{1,3}$, Qinglan Miao ${ }^{2}$, Baosan $\mathrm{Han}^{3, *}$ \\ ${ }^{1}$ The Second People's Hospitial of Jingmen, Jingmen 448000, PR China \\ ${ }^{2}$ College of Sciences, Shanghai University, Shanghai 200444, PR China \\ ${ }^{3}$ Xinhua Hospital Affiliated to School of Medicine, Shanghai Jiaotong University, Shanghai 200092, \\ China \\ *E-mail: hanbaosan@126.com
}

doi: $10.20964 / 2021.02 .38$

Received: 5 October 2020 / Accepted: 17 November 2020 / Published: 31 December 2020

\begin{abstract}
Hydrogen peroxide $\left(\mathrm{H}_{2} \mathrm{O}_{2}\right)$ has been widely used in various industries, including food production, pollution control, and textile bleaching. Therefore, it is necessary to determine its content for the sake of environmental and food safety. Silver nanoparticles (AgNPs) doped carbon nanofibers (CNFs) were prepared using electrospinning followed by calcination under a $\mathrm{N}_{2}$ atmosphere as a novel electrocatalyst for the sensitive detection of $\mathrm{H}_{2} \mathrm{O}_{2}$. The composition, structure, and morphology of CNFs doped with AgNPs (AgCNFs) were characterized using Raman spectroscopy, X-ray diffraction, and scanning electron microscopy. The electrocatalytic activity of $\mathrm{AgCNFs}$ towards $\mathrm{H}_{2} \mathrm{O}_{2}$ reduction was evaluated using cyclic voltammetry and amperometry. As determined by electrochemical studies, the developed electrochemical sensor displayed a broad dynamic range of $0.01-50 \mathrm{mM}$ and a detection limit of $3 \mu \mathrm{M}(S / N=3)$.
\end{abstract}

Keywords: Electrospun; Ag nanoparticles doped carbon nanofibers; $\mathrm{H}_{2} \mathrm{O}_{2}$; voltammetry.

\section{FULL TEXT}

(C) 2021 The Authors. Published by ESG (www.electrochemsci.org). This article is an open access article distributed under the terms and conditions of the Creative Commons Attribution license (http://creativecommons.org/licenses/by/4.0/). 